\title{
Orientation Program on the Care of Children Tracheostomized in the Home Environment
}

\author{
Cristiane Aparecida Moran1, Natalia Henrique de Almeida', Silvana Alves Pereira² \\ ${ }^{1}$ Nove de Julho University, Sao Paulo, Brazil \\ ${ }^{2}$ Ana Bezerra Hospital, Federal University of Rio Grande do Norte and EBSERH, Rio Grande do Norte, Brazil \\ Email: apsilvana@usp.br
}

Received 20 September 2014; revised 18 October 2014; accepted 27 October 2014

Copyright (C) 2014 by authors and Scientific Research Publishing Inc.

This work is licensed under the Creative Commons Attribution International License (CC BY). http://creativecommons.org/licenses/by/4.0/

c) (i) Open Access

\begin{abstract}
Objective: The aim of the study was to make a literature review on counseling and family education about the care with tracheostomy and develop a guidance booklet for parents about the cautions in handling tracheostomy tubes at home. Methods: This research is based on literature review from 1992 to 2012, realized from October of 2011 to August 2012, through the following databases: medline, lilacs, scielo and sibinet USP, with the elaboration of a guidance booklet for parents, about home care of tracheostomized children. Results: We elaborated a guidance booklet for parents, about the care of tracheostomized children and all were described according to literature review. Conclusion: According to the literature review family education in the care of tracheostomized children is essential so that caregivers have full autonomy to safely and effectively conduct the necessary techniques in their homes.
\end{abstract}

\section{Keywords}

Tracheostomy, Newborn, Child Care, Home Care Services

\section{Introduction}

The survival rate of newborns hospitalized in Neonatal Intensive Care Units has increased in recent years, due to professional training and advancement of mechanical ventilatory support [1] [2] and tracheostomy (TQT) is a feature that is often performed with an increase of its indication in children that are under one year old [3] [4].

The most common TQT indication is the prolonged tracheal intubation [4], where the permanency on mechanical ventilation may vary in average two months [5]-[7]. Several factors such as extubation failure, airway obstruction [5] [6], congenital malformation [4]-[8] and bronchopulmonary dysplasia are also indicatives for the realization of TQT [1] [9]-[11]. 
According to Edwards [12], children routinely remain with the TQT at home, being critical to have an adequate support and diligent planning for caregivers guided by health professionals.

The work of the multidisciplinary team in family education is essential for the prevention of complications such as accidental decannulation, [1] [3] [5] [12]-[16] obstruction of the cannula [4] [5] [16] pneumothorax [15], bronchopneumonia aspiration [7] stoma granuloma [1] [3] [16] and subcutaneous emphysema [4] [14]. The therapist assists in the process of the care with the TQT, clarifying and integrating the family to home care [3], orienting and training everyday skills [11].

The scientific literature shows several complications associated with the prolonged use of TQT, but no study reports the guidance and care in the household, in a practical way, for parents, showing the need of home assistance for caregivers of tracheostomized children.

The aim of this study was to present a literature review about family education and guidance for the care of tracheostomy, and elaborate a booklet of guidance to parents about cautions in handling tracheostomy at home.

\section{Method}

Research based on bibliographic review, conducted from October 2011 to August 2012.

The search for scientific articles was performed through medline, lilacs, scielo and sibinet USP database, with the descriptors: tracheostomy, child, newborn, child care, home care services; in Portuguese and English. Original articles and reviews about tracheostomy published between 1992 and 2012 were selected, being excluded articles with children over one year of age.

Later was elaborated a guidance booklet for parents, about the care of tracheostomized children (Figure 1).

\section{Results}

Orientations to parents about care with the child's tracheostomy were described, according to literature review, in Figure 1.

\section{Discussion}

According to published studies, family orientation about the process of care with the child's tracheostomy has been beneficial for caregivers who adapt to this new routine performing specific procedures, and for the child who can be cared for effectively in the home environment [3] [9] [17] [18].

In a study about the training with guidelines program, the authors concluded that home care can be as safe as hospital care [17], but the guidelines passed on to caregivers, do not cover only first world countries, according to a study made in South Africa, children can be safely cared for even in an environment with limited resources, but with the applicability of a program about education and appropriate orientation [18].

The consensus elaborated by Sherman et al., shows us that by the time the child goes home from the hospital it is necessary for parents or caregivers to undergo a specific home training given by health professionals [19]. Supported by Fiske which indicates how one of the main goals of a home-based program, the family's adaptation and interaction with the child [3].

Physiotherapy may help in the guidelines, clarifying doubts and helping the person responsible for the child to safely and effectively perform techniques at home [3] [11]. Recent studies demonstrate the importance of the multidisciplinary team, in discussing why the tracheostomy was performed in the child [11], didactically teach the anatomy of the airways and the respiration's physiology, so that the caregiver understands the changes that have occurred and the child's needs from this moment on [11] [20].

The upper airway of the individual heats, filters and humidifies the inspired air [3]. However, in tracheostomized children, the airway is ignored by the presence of the cannula and the air is not filtered and humidified, compromising the mucociliary activity. Consequently there is an increase in the production and thickening of the secretion [16] which may obstruct the TQT cannula [14]-[16]. Studies report that the use of the humidifier heats and humidifies the inspired air, keeping the mucus fluidized and reducing the risk of tube obstruction [11].

The aspiration of the TQT tube helps reducing the obstruction. The technique must be performed with caution and only when necessary, it is important not to exceed 15 seconds because it can cause hypoxemia [11]. Fraga [4], relate in their research that the aspiration of the TQT tube is primordial, because the tracheostomized child reduces the cough reflex, accumulating secretion in the tube. 
Cares with your baby's tracheostomy

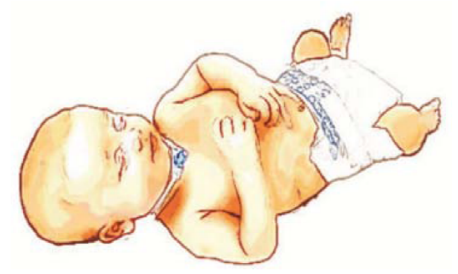

What is a tracheostomy?

Tracheostomy is an artificial airway, located in the neck. A tube is inserted into the trachea allowing the child to breathe spontaneously or with the assistance of a mechanical ventilator, bypassing the upper airways.

Participate in educational programs about home care.

Look for the hospital's physiotherapist to clarify questions on how to proceed with your baby at home.

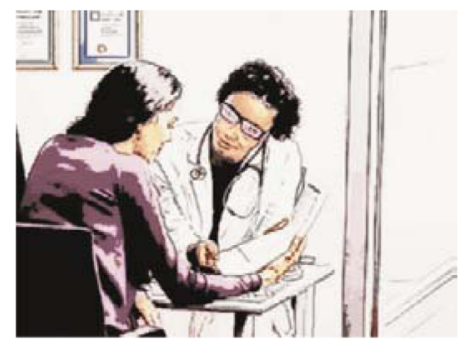

To evaluate your baby's conduct it is important to ensure appropriate care! In situations of respiratory distress the baby's face may turn a little purple, he/she may be restless, breathe quickly and audibly (which indicates, secrecy in the airways will increase).

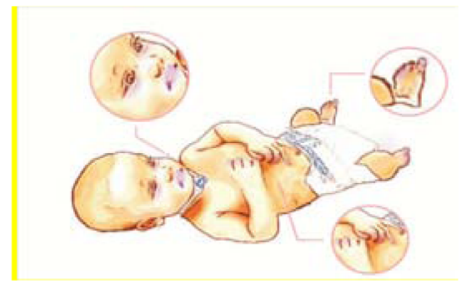

Suction of the tracheostomy tube.

It is of utmost importance to ensure a correct aspiration whenever the baby needs it because it eliminates the secrecy, promoting pulmonary ventilation, offering more comfort besides reducing the risk of infection and tube obstruction.

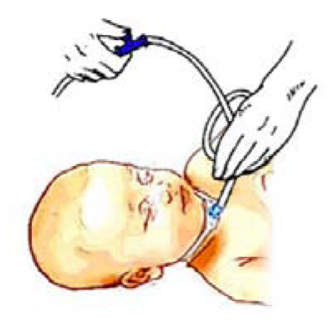

The importance of airway humidification.

The humidifier prevents the airways from getting dry, promoting the secretion's fluidization, reducing the risk of tube obstruction The weather can also alter the viscosity of secretions, drying out the air and making more frequent humidification necessary.
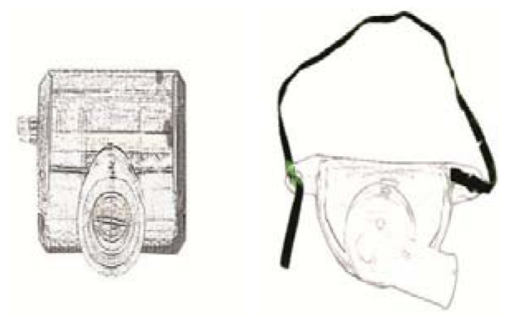

Sanitize the hole around the tracheostomy and the knot that holds it. 


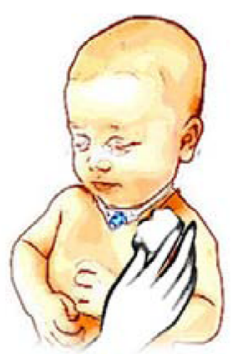

Clean around the tracheostomy at least twice a day, and whenever necessary, with water and mild soap. Stay attentive to any changes in the skin, such as redness, secretion and stench.

Seek medical attention if the baby's skin is irritated!

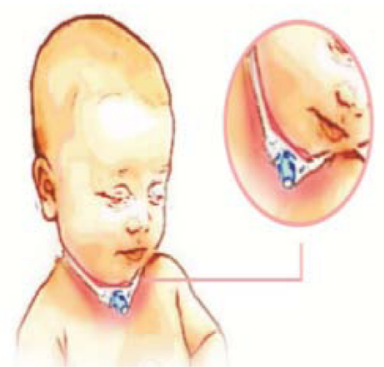

The knot holding the tracheostomy should be changed whenever it is wet or dirty, always tying it one finger away from the neck.

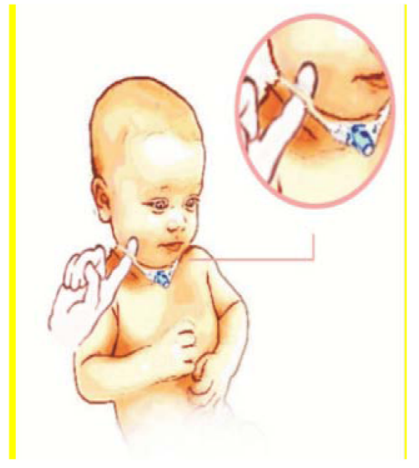

\section{Hygiene}

- Wash hands well.

- Use disposable gloves.

- Frequently change the suction tubes.

- Properly clean all equipments used.

- Avoid equipment exposure andmainly the baby's exposure to cigarette smoke, dust, animal hair and sprays.

- Adapt the baby's clothing; sweaters with turtlenecks may obstruct the air passage.

- During the bath water should notexceed the level of the abdomen and toys should be avoided.

\section{Figure 1. Guidance booklet for parents.}

The caregivers should be alert to signs that the child may present, including cyanosis, restlessness, tachypnea, increase of the respiratory work, audible breathing, desaturation and coughing. Such signs may indicate obstruction of the tube which is the main complication related to the TQT, which may lead the child to an emergency if the problem is not avoided [11].

The caregivers' daily practices with hygiene such as to wash hands and use disposable gloves, to frequently change the suction tubes and sanitize all equipments [3] [19] are fundamental in the home environment, because the respiratory system of the tracheostomized child is more prone to infections and performing aseptic techniques decreases the possibility of contamination [4].

The stoma should also be sanitized and frequently observed. Any change such as redness, fetid odor, rashes and signs of infection must be reported to the doctor [11]. These changes can be prevented with some care such as cleaning the air twice daily or whenever needed, with water and mild soap, using gauze and always keeping the 
spot dry [3], cares that reduce the chance of developing a stoma granuloma or subcutaneous emphysema in the child [13]-[16].

The material that fixes the tracheostomy must also receive care, it should therefore be changed whenever dirty or moist and tied a finger away from the neck [13] [19]. Materials for fixing the TQT tube on the child were settled by a consensus of the Pediatric Assembly of the American Thoracic Society, twill tape or velcro may be used. However the care must be the same to prevent moisture and consequently irritability in the child's skin [19]. Moreover, caution with the exposure of equipments used or the child itself to cigarette smoke, dust, animal hair and sprays, are also needed in home practice [3] [17].

The baby's garments also deserve attention because turtlenecks may obstruct the air inlet, and clothing should be carefully dressed to prevent accidental decannulation [3] [17]. The bath should be monitored at all times, water should not exceed the level of the abdomen and toys in the tub should be avoided because according to the study of Oberwaldner and Eber, children run the risk of bronchoaspirating them during immersion in water [17].

\section{Conclusion}

According to the literature review family education in the care of tracheostomized children is essential so that caregivers have full autonomy to safely and effectively conduct the necessary techniques in their homes.

\section{References}

[1] Pereira, K.D., Macgregor, A.R., Mcduffie, C.M. and Mitchell, R.B. (2003) Tracheostomy in Preterm Infants. Archives of Otolaryngology—Head \& Neck Surgery, 129, 1268-1271. http://dx.doi.org/10.1001/archotol.129.12.1268

[2] Edwards, E.A., O’Toole, M. and Wallis, C. (2004) Sending Children Home on Tracheostomy Dependent Ventilation: Pitfalls and Outcomes. Archives of Disease in Childhood, 89, 251-255. http://dx.doi.org/10.1136/adc.2003.028316

[3] Fiske, E. (2004) Effective Strategies to Prepare Infants and Families for Home Tracheostomy Care. Advances in Neonatal Care, 4, 42-53. http://dx.doi.org/10.1016/j.adnc.2003.11.011

[4] Fraga, J.C., Souza, J.C. and Kruel, J. (2009) Traqueostomia na criança. Jornal de Pediatria, 85, 97-103. http://dx.doi.org/10.1590/S0021-75572009000200003

[5] Pereira, K.D., Macgregor, A.R. and Mitchell, R.B. (2004) Complications of Neonatal Tracheostomy: A 5-Year Review. Otolaryngology_Head and Neck Surgery, 131, 810-813. http://dx.doi.org/10.1016/j.otohns.2004.07.009

[6] Romero, G.P., Pinto, J.M.P, Cano-Córtes, T.M., Ruiz, G.T., Garcia, M.M., Palomino, A.G., et al. (2005) Paediatric Tracheostomy. Acta Otorrinolaringológica Española, 56, 317-321.

[7] Itamoto, C.H., Lima, B.T., Sato, J. and Fujita, R.R. (2010) Indicações e complicações de traqueostomia em crianças. Brazilian Journal of Otorhinolaryngology (Impresso), 76, 326-331. http://dx.doi.org/10.1590/S1808-86942010000300010

[8] Zia, S., Arshad, M., Nazir, Z. and Awan, S. (2010) Pediatric Tracheostomy: Complications and Role of Home Care in a Developing Country. Pediatric Surgery International, 26, 269-273. http://dx.doi.org/10.1007/s00383-009-2494-8

[9] Messineo, A., Giusti, F., Name, S., Mognato, G., Antoniello, L. and Guglielmi, M. (1995) The Safety of Home Tracheostomy Care for Children. Journal of Pediatric Surgery, 30, 1246-1248. http://dx.doi.org/10.1016/0022-3468(95)90034-9

[10] Berry, J.G., Graham, R.J., Roberson, D.W., Rhein, L., Graham, D.A., Zhou, J., et al. (2010) Patient Characteristics Associated with In-Hospital Mortality in Children Following Tracheotomy. Archives of Disease in Childhood, 95, 703710. http://dx.doi.org/10.1136/adc.2009.180836

[11] Joseph, R.A. (2011) Tracheostomy in Infants: Parent Education for Home Care. Neonatal Network: The Journal of Neonatal Nursing, 30, 231-242. http://dx.doi.org/10.1891/0730-0832.30.4.231

[12] Sousa, A., Nunes, T., Roque Farinha, R. and Bandeira, T. (2009) Traqueostomia: Indicações e complicações em doentes pediátricos. Revista Portuguesa de Pneumologia, 15, 227-239.

[13] Marsico, O.S. and Marsico, G.A. (2010) Traqueostomia. Pulmão RJ, 19, 24-32.

[14] Midwinter, K.I., Carrie, S. and Bull, P.D (2002) Pediatric Tracheostomy: Sheffield Experience 1979-1999. The Journal of Laryngology \& Otology, 116, 532-535. http://dx.doi.org/10.1258/002221502760132403

[15] Schlessel, J.S., Harper, R.G., Rappa, H., Kenigsberg, K. and Khanna, S. (1993) Tracheostomy: Acute and Long-Term Mortality and Morbidity in Very Low Birth Weight Premature Infants. Journal of Pediatric Surgery, 28, 873-876. http://dx.doi.org/10.1016/0022-3468(93)90685-E

[16] Amin, R.S. and Fitton, C.M. (2003) Tracheostomy and Home Ventilation in Children. Seminars in Neonatology, 8, 
127-135. http://dx.doi.org/10.1016/S1084-2756(02)00220-8

[17] Oberwaldner, B. and Eber, E. (2006) Tracheostomy Care in the Home. Paediatric Respiratory Reviews, 7, 185-190. http://dx.doi.org/10.1016/j.prrv.2006.06.003

[18] Vanker, A., Kling, S., Booysen, J.R., Rhode, D., Goussard, P., Heyns, L., et al. (2012) Tracheostomy Home Care: In a Resource-Limited Setting. Archives of Disease in Childhood, 97, 121-123. http://dx.doi.org/10.1136/adc.2010.187153

[19] Sherman, J.M., Davis, S., Albamonte-Petrick, S., Chatburn, R.L., Fitton, C., Green, C., et al. (2000) Care of the Child with a Chronic Tracheostomy. This Official Statement of the American Thoracic Society Was Adopted by the ATS Board of Directors, July. American Journal of Respiratory and Critical Care Medicine, 161, 297-308.

[20] Lewarski, J.S. (2005) Long-Term Care of the Patient with a Tracheostomy. Respiratory Care, 50, 534-537. 
Scientific Research Publishing (SCIRP) is one of the largest Open Access journal publishers. It is currently publishing more than 200 open access, online, peer-reviewed journals covering a wide range of academic disciplines. SCIRP serves the worldwide academic communities and contributes to the progress and application of science with its publication.

Other selected journals from SCIRP are listed as below. Submit your manuscript to us via either submit@scirp.org or Online Submission Portal.
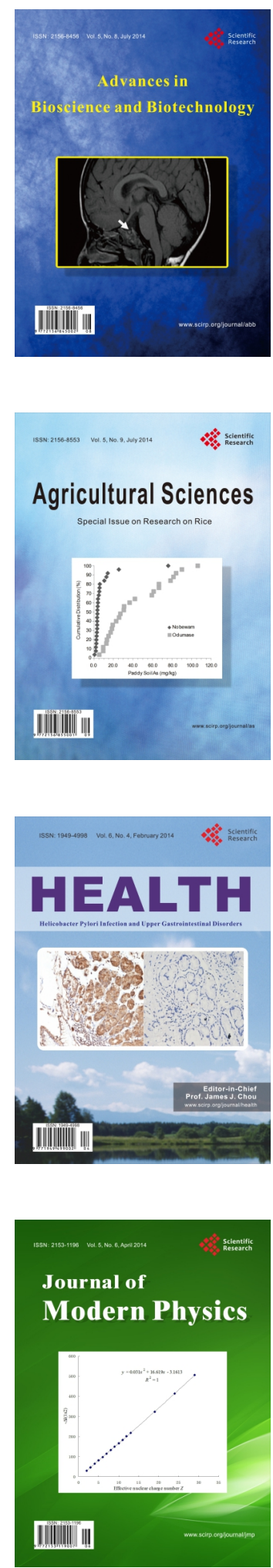
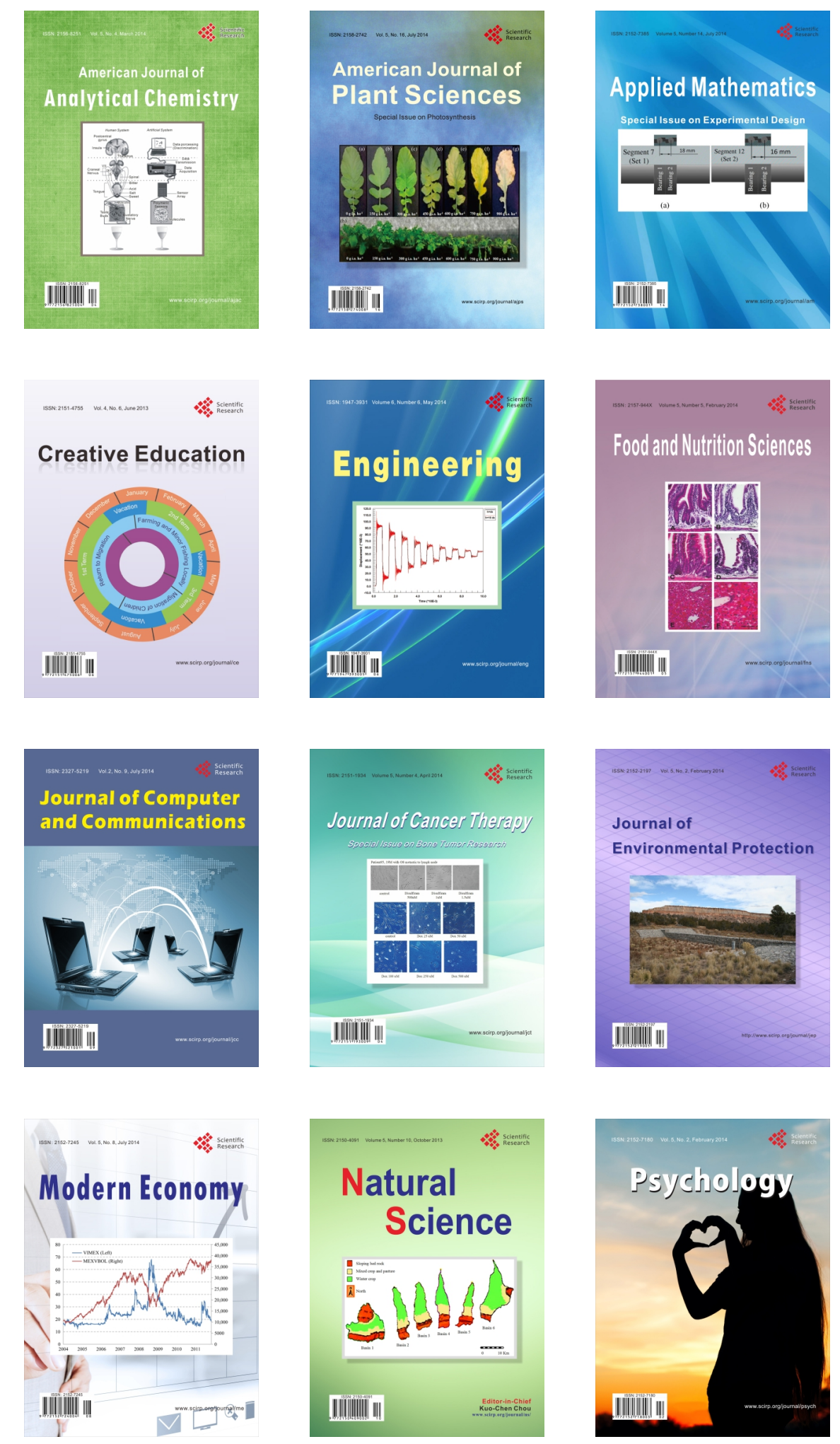